\title{
CLASS, SOCIAL SUFFERING AND HEALTH CONSUMERISM
}

\section{Camilla Hoffmann Merrild, Mette Bech Risør, Peter Vedsted and Rikke Sand Andersen,}

\section{ABSTRACT}

In recent years an extensive social gradient in cancer outcome has attracted much attention, with late diagnosis proposed as one important reason for this. Whereas earlier research has investigated health care seeking among cancer patients, these social differences may be better understood by looking at health care seeking practices among people who are not diagnosed with cancer. Drawing on long-term ethnographic fieldwork among two different social classes in Denmark, our aim in this article is to explore the relevance of class to health care seeking practices and illness concerns. In the higher middle class, we predominantly encountered health care seeking resembling notions of health consumerism, practices sanctioned and encouraged by the health care system. However among people in the lower social class, health care seeking was often shaped by the inseparability of physical, political, and social dimensions of discomfort, making these practices difficult for the health care system to accommodate.

Running title: Health care seeking contextualized

Key words: Cancer, Denmark, health care seeking, health consumerism, social suffering

Media teaser: Health care seeking is practiced differently by people from different social classes when they experience illness concerns. Why may this be so? 


\section{Bio notes}

Camilla Hoffmann Merrild is a PhD fellow at Research Unit for General Practice, Research Centre for Cancer Diagnosis in Primary Care, Aarhus University. Her research centers on social inequality and social differences in perception and management of the body. Direct correspondence to: Research Unit for General Practice, Research Centre for Cancer Diagnosis in Primary Care, Bartholins Alle 2, 8000 Aarhus, Denmark. E-mail: Camilla.merrild@ph.au.dk.

Mette Bech Risør is a professor of anthropology. Her research has primarily focused on functional disorders, but her work also extends to other areas of symptom and illness perceptions and practices. Direct correspondence to the General Practice Research Unit, Department of Community Medicine, UiT The Arctic University of Norway, 9037 Tromsø. E-mail: mette.bech@uit.no.

Peter Vedsted is a Professor of Primary Care at The Research Unit for General Practice, Professor of Innovative Patient Pathways at Silkeborg Diagnostic Centre, and Director of the Research Centre for Cancer Diagnosis in Primary Care, Aarhus University. He has published extensively on early diagnosis of cancer. Direct correspondence to: Research Centre for Cancer Diagnosis in Primary Care, Aarhus University, Bartholins Alle 2, 8000 Aarhus, Denmark. E-mail: p.vedsted@feap.dk.

Rikke Sand Andersen is an associate professor. Her research primarily focuses on health care seeking, cancer diagnosis and the organization of primary care. Direct correspondence to:

Department of Culture and Society, Section for Anthropology, and the Research Unit for General Practice, Research Centre for Cancer Diagnosis in Primary Care, Aarhus University, Bartholins Alle 2, 8000 Aarhus, Denmark, E-mail: $\underline{\text { rsa@feap.dk. }}$ 
Based on long-term, comparative ethnographic fieldwork among two different social classes, in this article we illustrate how health care seeking practices are embedded in everyday life and shaped in the tension between notions of health consumerism and degrees of social suffering. The setting is Denmark, a Nordic welfare state of 5.6 million people, built around notions of universality and homogeneity. Since the 1933 Social Reform Act, welfare schemes covering the entire population and financed through taxation have been implemented (Jöhncke 2011). These schemes cover many areas, including free education, sickness benefits, pensions, child care facilities, and health care. All primary and secondary health care services are provided free of charge, with general practice serving as the gatekeeper for specialized treatments. Yet despite the extensive welfare system, Denmark is witnessing growing social differences and a recent study mapping social cohesion of in Denmark has referred to it as an invisible class society (Olsen, Ploug, Andersen and Juul 2012). Building on statistical analyses of educational and economic position, Olsen and colleagues (2012) show how nearly 25 percent of the adult Danish population between 18 and 59 years of age belong to the middle class, 10 percent to 'higher' social classes, and 66 percent lower classes. The authors define the middle class as independent businessmen, senior executives or people with short or middle-range educations who earn less than twice the average income in Denmark, which was 60 000 USD in 2012 (Sabiers and Larsen 2014). The lower social classes are defined as skilled and unskilled workers and people out of the workforce for 80 percent of the year; and the higher social classes are defined as independent businessmen and women, senior executives, people with high education earning more than twice the average Danish income, and all university graduates independently of their income (Olsen, Ploug, Andersen and Juul 2012:37). These social differences translate directly into health and people from the lower social classes carry a higher burden of both morbidity and mortality (Pickett and Wilkinson 2014). In 2009, the absolute difference in life 
expectancy between the two quartiles of 30-year-old Danish males with the highest and the lowest income was almost ten years, while the corresponding number for women was six years (Baadsgaard and Brønnum-Hansen 2012).

Accounting for 31 percent of all deaths in Denmark in 2012 (Statens Serum Institut 2013), cancer reflects the growing social inequalities and class differences in health in Denmark (Olsen et al. 2012). Numerous studies have shown that people from lower social classes get cancer more often and are more likely to die from it (Coleman et al. 2011; Dalton et al. 2008; Rachet et al. 2010; Woods, Rachet, and Coleman 2006). The processes leading to social inequality in cancer survival are, however, difficult to map. Differences in stage of cancer at the time of diagnosis or treatment have been suggested as major factors explaining inequalities in survival (Dalton et al. 2011; Frederiksen et al. 2008; Ibfelt et al. 2012; Woods, Rachet, and Coleman 2006). One explanation for this may be differences in communication between GPs and people from lower social classes, which have an impact on the information exchanged in clinical encounters (Willems et al. 2005). Thus, Willems and colleagues (2005) showed that the somewhat passive communicative style of people from lower social classes in clinical encounters resulted in misunderstandings of the intents and desires, leading to less information being shared. These experiences in turn potentially discourage early care seeking. A number of epidemiological and public health-based studies have hypothesized that these differences may partly be influenced by differences in health care seeking practices; and it has been suggested that people from lower social classes may be more likely to postpone medical advice when experiencing potential signs of cancer (e.g. Lyratzopoulos et al. 2013; Macleod et al. 2009). In the literature on early cancer diagnosis and health care seeking, raising public awareness of the so-called 'alarm symptoms of cancer' is often suggested as a means 
to reducing social disparities in cancer survival (e.g. Ibfelt et al. 2012; Lyratzopoulos et al. 2013; Macleod et al. 2009; Whitaker et al. 2015). Hence, 'timely' and 'correct' symptom recognition is conceived as triggers of early health care seeking, and the public is encouraged to seek health care as early as possible, and to be attentive towards and to respond to a variety of sensorial markers designated 'alarm symptoms of cancer' (e.g. Hamilton et al. 2009). This 'awareness' perspective may be challenged in a number of ways, as we discuss later. Identifying cancer alarm symptoms, and deciding when to seek health care 'in due time', is not as straightforward as often suggested in the public health literature (Andersen, Tørring, and Vedsted 2014). The classification of certain bodily changes and experiences as 'alarm' symptoms of cancer was developed to quantify the probability of having a particular cancer disease, given the experience of 'a specific bodily change'. However, epidemiological research on cancer symptomatology suggests that 'alarm symptoms' are common (Svendsen et al. 2010) and have low positive predictive values for cancer (Hamilton et al. 2009). This led Andersen, Tørring and Vedsted to argue that "symptoms of cancer are equally invisible and potentially omnipresent, reflecting a generally high level of statistical uncertainty in regard to defining characteristics of bodily signs of disease which constitute a need of medical assistance” (2014:3-4).

The case of cancer is illustrative of existing social inequalities in health in Denmark. It also allows us to engage with current developments in the general thinking and manifestation of health promotion discourses related to early disease detection. To understand how health care seeking is triggered, it is however necessary to explore how health care seeking is embedded in everyday life, and practiced by people who do not have cancer but are expected to proactively respond to more or less common symptoms, rather than to retrospectively focus on triggers of health care seeking after 
cancer has been diagnosed. In this way, we hope to contribute to understanding social differences in the timing of cancer diagnosis. This leads us to challenge the idea that the primary barriers to early health care seeking are grounded in symptom appraisal and lack of awareness. In this article, we argue that information campaigns referring to awareness of cancer symptoms to ensure timely health care seeking fail to take account the social and cultural embeddedness of bodily experiences and health care seeking practices. We suggest that bodily experiences and decisions to seek medical advice are tied to forms of social suffering, intrinsically linked with the politics and economies of life generated by social conditions and constituted as an embodied social process in persons (Ceres 2011; Kleinmann, Das, and Lock 1997).

\section{THE PATIENT AS A CONSUMER}

The social science literature has recently emphasized the role of biomedicine in shaping contemporary forms of subjectification, bodily practices, assumptions, and attentiveness (Rose 2007; Shilling 2002). According to sociologist Nikolas Rose, technological advancements in biomedicine and novel conceptions of biological citizenship have resulted in a re-coding of duties and the growth of a somatic ethics, whereby people increasingly experience, articulate, judge, and act upon themselves (and others) in the language of biomedicine to maintain the body's wellbeing and functioning (Rose 2007:25-26). These developments, argues Rose (2007: 25-26). argues, are reinforced by the normative power of official health promotion discourses, wherein the body and its well-being have become the center of 'moral judgments',; of good and bad,; encouraging people to become active and responsible consumers of medical products and services. Inspired by this thinking and immersed in the significance of developments in biomedicine, other researchers, more 
focused on health care seeking practices, have suggested that lay people are moving towards a more 'consumerist' approach when seeking health care (Shilling 2002; Lupton 1997). Being a 'consumerist patient', in Shilling's terminology (2002:628), implies an increased attention to the body, but it also refers to more subtle notions of the body as a vehicle for gratification, for pleasure, and for self-cultivation. Overall, this literature refers to the body's changing status and its wellbeing as something no longer just 'taken for granted', but at the center of our attention and commands our resources, now, so to speak, open 'to investments' (Shilling 2002:627). consumer is thus a subject concerned with health and engaged in and able to seek information about the body's maintenance and optimization, and so 'consumes' health care as a service that may maximize well-being and protect the subject from the adversities of poor health (Lupton 1997, Rose 2007, Shilling 2002). Health consumerism therefore refers to individual practices of the body, which are reinforced and supported by the health care system. A wide range of 'patient centered' approaches are being introduced into the healthcare system, and with varying degree of intensity, these initiatives address and activate patients as users of healthcare services. Being allocated a 'user identity' has thus become central in current organizational healthcare to promote empowerment strategies and involvement in care and diagnostic process. Such initiatives in many ways feed into health consumerism.

Biomedicine is an important factor in shaping bodily perceptions or practices, but little attention has been devoted to the conditions under which the patient as a consumer materializes in specific socio-political contexts. However, Lupton (1997:379-80) points out how a focus on consumerism may ignore a number of complex aspects of health care seeking, such as the embodied and affective dimensions of illness and the unequal power relation intrinsic to the clinical encounter. More recent studies focusing on social groups and the management of health care in less 
affluent settings demonstrate considerable social differences in modes of appropriation, including the moral discourses underlying health practices and beliefs in different social and cultural classes (Garro 2011, Karasz and Dempsey 2008). These works illustrate the intrinsic tie between health and wellbeing and the concerns and demands of the enactment of everyday life. The materialization of bio-power or the construction of the 'health consumer' is thus, in the words of Susan Whyte (2009:10), not given, but an empirical question that calls for comparative ethnography.

Against the back-drop of current health promotion discourses as they materialize in the case of cancer, we explore the conditions for, and emphasize the dynamic and intersubjective processes that shape, health care seeking practices departing in the writings on social suffering (Kleinman, Das and Lock 1997) and health consumerism (Shilling 2002). We explore health care seeking practices as they unfold in two different social classes in Denmark. We argue that they materialize in the tension between notions of health consumerism and degrees of social suffering. We point out how the adverse influence of social, political, and economic hardship produces embodied forms of suffering discordant with proactive approaches to health care seeking practiced by the health consumer or portrayed by the image of the patient as a service user. We take experiences of social suffering among lower working class informants, socially and physically informed by the larger socio-political structures, and partly grounded in unemployment, deteriorating family relations, stressful and sometimes violent lives as well as poor health. In attending to the different forms of social suffering "resulting from what political, economic, and institutional power does to people, and, reciprocally, from how these forms of power themselves influence responses to social problems” (Kleinman, Das and Lock 1997:ix), we move closer towards an understanding of the different conditions framing health care seeking practices and the socially diverse manifestations of health promotion discourses. 


\section{METHODOLOGY}

This study draws on material collected over 12 months of fieldwork carried out by the first author in 2012-13. The fieldwork was conducted with people from two different social classes in two different neighborhoods suburban Denmark. In order to access different social classes, the neighborhoods were selected based on a combination of population composition and context analysis (Larsen 2010). Those informants who, in a descriptive sense, we have termed higher middle class (HMC) informants, all owned houses in an attractive, high-status residential area, where the property value was generally set above USD 600,000 (an average one-family home costs about USD 300,000, depending on geographical location) and were either university graduates and/or had a financial position above that of the average Danish income earner. Informants who, in a descriptive sense, we termed lower working class (LWC) informants all rented their apartments in a socially deprived housing association in an area with high unemployment rates. They either had no formal education or short-term vocational training; at the time that they were invited into the study, they had all been living on welfare benefits for at least the past year.

In total, we invited 12 key informants from the identified neighborhoods selected through purposeful sampling (Bernard 2011:192-93); six from the LWC and six from the HMC. The 12 informants were approached during social arrangements in the two selected settings, and invited to participate by the first author. They were giving written information regarding the project, and subsequently contacted by telephone to verify their continued interest in participating and to answer any potential questions they might have. The informants were an equal mix of men and women; some were single, some cohabiting, and some married. Using participant observation, the first author followed all key informants regularly in their everyday lives during a 12-month period, participating in a wide range of everyday activities such as 'hanging out' at home, grocery 
shopping, playing golf, other leisure activities, social events in the housing association, visiting the general practitioner (GP), and job activation. After each field visit, extensive field notes were written. As many of the field visits took the form of social activities, relationships developed with family and friends belonging to the same social classes as the key informants, thereby extending the group of informants beyond the 12 key informants. Accordingly, the ethnography was "situated less by a discrete place...than by interpersonal relationships", and the field was where the key informants were (Clifford 1997:189).

Each key informant was formally interviewed three times over the 12 months of fieldwork, and the interviews were recorded and transcribed verbatim. All key informants also filled out symptom diaries over a period of three months, recording any experiences of symptoms or discomforts and how these were managed. The symptom diaries were used as points of departure in one of the interviews, where specific symptom experiences were explored. Both interview transcripts and field notes were subsequently coded using NVivo 10. The text was analyzed through focused coding, and thematic patterns were identified and analyzed in a dialectic process moving between empirical data and analytical reflection (Emerson, Fretz, and Shaw 2010).

The project was conducted in accordance with the Code of Ethics of the American Anthropological Association (American Anthropological Association 2012) and was approved by the Danish Data Protection Agency (j.no. 2012-41-0866). All informants and neighborhoods have been anonymized and given fictive names, and any information which could potentially identify the participating individuals has been left out.

STUDYING SOCIAL CLASS 
class is a culturally and discursively constructed category (Ortner 2003), yet, at the same time the statistics outlined in the introduction suggest that unequally distributed material resources, based primarily on educational and financial position, need to be taken into account in Danish society. However, economic difference is merely one aspect of social inequality; social inequality also manifests in health status, management of the body, life modes, and lifestyle. These are all produced and reproduced by the very contrast of the daily lives of distinct social classes (Bourdieu 1984; 1987; Ortner 2003).

The comparative character of the fieldwork reported here emphasized these different physical and social dimensions of class. Continuously shifting between discussions and concerns related to the forced removal of children from home, assaults, prolonged unemployment, recurring depression, and the strains of physical challenges such as being overweight, managing galloping sugar levels, and irregular heartbeats among people in the LWC were in stark contrast to the concerns of the HMC which included, among other things, managing holiday houses abroad, exotic travel, and stimulating activities with friends and family, along with descriptions of how the body was kept in shape through various leisure activities and dietary measures. All informants were outside the formal labor market. But whereas all but one informant in the LWC were clients with the national government social services, and all were living off different forms of social welfare, the HMC informants were retired and living off their assets or private pensions. Thus, there were great differences between the two classes in terms of how they were influenced by the institutional political, economic, and social powers, and how they shaped the practice of their everyday lives. These differences were striking at emotional and at physical levels, and in the autonomies of their different social lives. Different conditions of existence produced and structured different ways of being in, acting on, and perceiving the social world (Bourdieu 1984), demonstrating how economic, 
social, and cultural differences were produced and reproduced in people's daily lives. In the following we provide ethnographic illustrations of the two different settings, and explore how health care seeking is practiced by these two groups. The cases presented here do not represent ‘perceived cancer symptoms’, but are meant to illustrate how common health care seeking practices

and symptom experiences are embedded in everyday life worlds, their politics and their hardships. They are selected for their representativeness and reflect the patterns of health care seeking found among the two social groups, illustrating differences between the two social classes and the difficulties that people face in determining or defining 'with what' and when to 'legitimately' seek medical advice.

\section{PRACTICING HEALTH CARE SEEKING}

\section{Consuming health}

From the outset of fieldwork, it became clear that mobility and physical activity was highly valued by the HMC informants. Although retired and living on their assets, they kept busy schedules, packed with different kinds of leisure activities such as golfing, gymnastics, attending courses and lectures, taking care of grandchildren, and spending time with friends. In their everyday life they were very conscious about maintaining their health so that they could keep up this lifestyle: they were attentive towards their bodies, and continuously kept track of their health by using various assistive devices such as bathroom scales and sphygmomanometers to measure blood pressure. Although specific health problems were rare, they frequently made use of health providers including their GP, dieticians, and physiotherapists. Often, when irregularities were found, the GP was consulted, and specific checkups were frequently requested for examinations for prostate 
cancer, blood tests, and general health checks, and the like. As Esther, a retired but well-to-do woman in her sixties explains;

We feel that when we reach 50 - 55 years of age or something like that, then we book an appointment with the GP in order to have what we call a 50,000 kilometer service. Then we need to have our blood pressure and that kind of thing checked ... And, well ... that is something we have decided. Tom (her husband) has actually always done it. He has always been very conscious about wanting to, well, to have different things checked out. Blood tests and so on... And then I also asked to have a total examination. And I got it.

Like many other HMC informants, Esther’s health care seeking practices resemble what we could characterize as a 'consumerist' approach to health care (Shilling 2002). These health care seeking practices illustrate how some people take responsibility for proactively maintaining good health and preventing illness; and how attentiveness towards potential bodily irregularities becomes an imperative of personal values and ambitions for the 'good life'. They also illustrate how health care, in this setting, is approached in the same way as other products and services (Conrad 2007:138) utilized to enhance or ensure a productive and pleasurable life. As Esther has described, she wants to know if she has any physical problems that she should be aware of so that she can act proactively; she expects a clear and precise response or result; and her expectations are enabled by the increasingly technical, specialized, and proactive diagnostic practices of medicine.

In this spirit, Esther regularly visits her GP and has blood tests taken to keep track of her cholesterol, and sometimes these tests show irregularities. The latest blood test indicated a problem with her liver, and when Merrild came to visit her shortly after, she looked solemnly as she explained: 
E: I have some news today. You know I have my cholesterol checked with my GP. And last time, they found that the numbers indicating my muscle enzymes were too high. I asked what it meant, and if it was dangerous, but they told me it wasn't because it was not that high. Then I had the blood test taken again, but for two weeks I did not hear from them. So I called down there to ask a few days ago, and he (the GP) told me that I had increased liver values. And, of course, it is all connected. So I was referred to an ultrasound at the hospital, and they called me yesterday. I have to come down there today at 1pm.

C: Ok. (We sit together in silence for a little while). And what do you think about that?

E: Well, of course, I am worried, and imagine the worst, cancer as the ultimate worst, and all kinds of other things ...

$\mathrm{C}$ : But is it because it happens so fast?

E: Yes it is. And that they called me. I have not even gotten an invitation, or signed anything saying that I wanted to be called in if they had a cancellation. But what upsets me most is that I would not have found out about it if I had not called them myself and pressed for the results from those tests. And now, I worry that it is the medicine I have been taking, which has been bad for me. I have suspected it all along. And it is all connected, because it all started way back when I had my liver scanned, at my own expense, at that private clinic. I have always worried about that liver; and back then, I was told it was a fatty liver, nothing else.

As this example makes clear, Esther does everything she can to ensure her good health so that she can remain fit and active and continue to play golf and play tennis several times a week, work in her garden, take care of her home and her grandchild, and so on. She has continuously been attentive towards her liver and has proactively reacted on vague, ambiguous, but potentially serious, sensations. In this case, her proactivity eventually caused her much concern and suffering, as she 
suddenly found herself at risk of serious illness and "cancer as the ultimate worst." It adds to her distress that the health care system has seemingly delayed transmitting her test results and so has failed to meet her demands of proper service provision.

By pointing out the consumerist ethos, we wish not to suggest that proactivity and attentiveness were always accommodated when health care was sought by people in the higher social classes. This is evident for Charlotte, another HMC informant in her early sixties, also retired and living off her assets. Like Esther and other HMC informants, Charlotte wants to keep her body in check; and to do so, she wants an expert's opinion regarding her specific problem:

I think that I have had difficulties getting through ... I think that I might as well just write an email to my GP saying that I would like to have a scan for that osteoporosis, because I have had this recurring back pain. But it doesn't work that way. No, I have to come down here first, because we have to have a chat about it. Then she gets paid for a consultation again, right? And that annoys me... That you can't ... Because I am so familiar with myself and my body and the (health care) system that I know that I have the right to get that scan, for example, for osteoporosis. But, no, I have to go down there (to the GP) first... Have a little chat and... Well, last time I was there, I actually asked directly for a referral to a gynecologist. I didn’t get that.

The experience of not being able to get through to a specialist was often recounted by the HMC informants, and it caused them considerable suffering and distress. Yet, whether the service is provided according to the patient's wishes or not, what stands out is that health care seeking springs from a proactive and attentive orientation towards the body, and that it is practiced in a direct and matter-of-fact way. Health care, whether from examination, treatment, a referral, or a prescription, was service by HMC informants. These services could be the object of intentions, expectations, and 
even claims. This approach makes sense when viewed within the context of the social conditions shaping the lives of the HMC; their relative affluence, independence, and high social position shielded them from social, political and economic hardships and social suffering. The imperative of maximizing lifestyle, potential health, and quality of life, which Rose (2007:25) refers to as somatic ethics, become possible only when political, economic, and social forces do not infringe on the practice of everyday life.

Esther's and Charlotte's experiences illustrate that health care seeking practices as they materialize in the HMC are approximations of health consumerism, resembling what has been called 'proactive perceptions' and practices of health and the body (see also Bourdieu 1987, Lupton 1995, 1997, Shilling 2002). Our empirical findings echo those of Katz (2000), who illustrates the imperative connections between activity and wellbeing in aging populations by the so-called disciplinary discourse on the management of everyday life. Like participants in Katz's study, the HMC informants were all pensioners and their somewhat advanced age perhaps increased their focus on maintaining their good health and preventing illness. However, studies with younger participants have reported similar findings; the conceptual models of cause and cure are rooted in the body as an individual project in some populations (Karasz and Dempsey 2008). For some populations, therefore, reducing potential health risks is an imperative, wherein "numerical results of check-ups and home monitoring are appreciated and became central in individual processes of taking control over and responsibility for one’s health” (Andersen and Whyte 2014:266). Such practices also resonate with a proactive attentiveness towards sensations and symptoms potentially indicating disease, especially cancer. Although attentiveness and proactive presentation may be promoted in health care seeking discourses related to early diagnosis, this does not always reverberate with the ways in which trouble and illness is addressed among people in the LWC. 


\section{Dealing with multiplicities of trouble and disease}

A striking experience when getting to know the informants in the LWC was the significance of state social services in their lives. They were, as indicated above, all out of the workforce and living of social welfare benefits, and therefore dependent on social services. Their lives were shaped by haphazardness, adversity and a sense of calamity, as Fanny's case illustrates. Fanny had moved 26 times before she turned 18. Both her parents were alcoholics; and as the oldest, she often had to assume responsibility by taking care of her siblings. She left school after the ninth grade and has had various jobs since. Before she met her present partner, she lived in a violent relationship for a number of years, which eventually ended in great trauma and dispute over their children. All her four children have special needs, and the oldest has lived in an institution since he was six years old. For the last four years, Fanny has been a client with social services, living off welfare benefits. She has been sent back and forth between different job trainings, but she has been unable to fulfill the demands of these due to severe pain in her shoulder, her hand, and sometimes her arm. Fanny blames the pain on her many years of working in a factory, where she had to assemble minor parts with very small repetitive movements for long periods of time. She is hoping to be allocated early retirement pension, but according to regulations, social services must continuously try to find her a job that she can manage. Every time she is asked to attend new job trainings, the work exacerbates her pain and associated paresthesia. The social services regularly encourage her to visit her GP to follow up on her diffuse and shifting pain. Fanny is reluctant to follow their advice, but as her pain gets worse, she eventually schedules an appointment with her GP. Merrild accompanied Fanny to the appointment, and after waiting 30 minutes in the waiting room, Fanny was called into the consultation room. 
The GP gives Fanny a quizzical glance and Fanny says that her arm is causing her trouble again. She constantly feels a tingling sensation. The GP takes Fanny's hand and puts pressure on her wrist. “Can you feel this”, she asks, “is something happening now?” "It hurts and tingles”, Fanny replies, and her hand makes a few spasms. While the GP is examining her hand, Fanny says that the social services have asked if she could be referred to a neurologist. “A neurologist can’t help you with this", says the GP, "there is a problem with the blood flow, and it may be due to overexertion, but overweight may also have something to do with it.” Fanny immediately begins to explain how they have made her wash the floor during job training sessions, but the GP cuts her off by saying that she wants to finish explaining, and she continues her elaboration about how the veins and wrist are connected, and how the blood flow can be cut off. "So it might help if you lose some weight," the GP concludes. Fanny responds that she is already doing that; she has lost $20 \mathrm{~kg}$ in the past year. "The rest is just a little baby fat," she says, smiling. The GP laughs, but then stops, as if realizing that Fanny was not making a joke. The GP suggests that surgery might help her, and that she can refer Fanny so that a surgeon can check the blood flow. "But it depends on how much time you have, because it could very well be that losing some weight might solve the problem.” Fanny explains that she has a meeting with the social services next week, where they will consider sending her for another job training session, and she can’t stand having to go through that again. The GP concludes that she needs the referral so that the surgeon can decide on how bad it is, or whether she just needs to lose some weight.

Fanny leaves the consultation with a referral to surgery. The GP addressed the health problem with which Fanny approached her - the pain in her arm - but as Fanny asks the first author later, "if this is solved, then what about the rest?” Fanny’s suffering extends beyond the pain in her arm. As with all LWC informants, she has a number of physical and social problems. For instance, she 
suffers from severe abdominal pain and repeated and unexplained incidences where she has stopped breathing; these concerns never make it to the consultation room. most impending challenge is the social services' increasing demands, and these overshadow most of her other problems. This very clearly reflects how social suffering is intrinsically tied to the politics and economies of life, generated by social conditions and embodied (Ceres 2011:3, Kleinman, Das and Lock 1997). Living on welfare benefits in Denmark brings with it a number of demands, like attending job training. If these demands are not met, the social services may withdraw financial support, leaving the welfare recipient with nothing. This means that the social services play a vital role in controlling and directing Fanny's life, in the sense that its officers have the power to demand that she tries out different jobs and performs certain activities.

If we consider that the pain in her arm is an embodiment of social class, it becomes clear how Fanny's unemployment and dependence on welfare benefits has subjected her to the demands of the social services, which shape and reinforce her physical pain. Her very concrete pain, inflicted by the work situations which she cannot manage, e.g. washing floors and lifting heavy things, is the concrete manifestation of her suffering. Fanny's health status is partly influenced by the formal requirements of the welfare state. Her suffering is played out as diffuse pain, reinforced by the institutionalized requirements of welfare state policies, requirements that may make more intractable the problems they seek to alleviate.

It might be argued that social suffering is a somewhat 'dramatic' concept to use in a Danish social welfare context. Nevertheless, examining health care seeking from the perspective of social suffering underscores the social adversity experienced by LWC informants, and highlights the different positions from which people seek care. Simultaneously, it challenges reductionist perspectives on 'what counts as a legitimate medical object' in the clinical encounter, resembling 
what Mik-Meyer and Obling address as the classification of patients in legitimate sick roles (2012:1026). This is clearly illustrated by Brian, who has been living on early retirement benefits for the past ten years and who has multiple somatic and psychiatric diagnoses:

I really don't think that if you go to see your GP, then you go there to tell her, well for instance, that you are just feeling bad. But why are you feeling bad? She has to try to understand what is going on with this person. Because it is the person... When you go to see your GP, then it is you as a person it is all about ... She asked me if I had been stressed out lately, and then I told her; no, except my mom is dying, my daughter is losing her unborn child to the social services, and I have had prostate cancer, I have high blood pressure, asthma and diabetes, then no, I don’t think much is going on at the moment.

People from lower social classes often carry heavy and complex social histories in addition to multiple diseases. Brian and Fanny are not atypical. As Brian explains:

I can’t walk properly. I feel pain everywhere because I am too fat and... my knees hurt and... He (the GP) doesn't see me as a whole person. It is just like, ok, this is this and that is what he tells me. I have tried to ask him if all the different things may have something to do with each other ... If we can look at it as a whole, but no, I can have a general health check and some blood tests and then we can see ... No, I don't feel like talking to him, so I have stopped going.

Brian's and Fanny's situations highlight the social suffering of informants in the LWC, where the increasing demands to proactively attend to, and seek care for, potential alarm symptoms are challenged by competing concerns in relation to unemployment, poverty, and deteriorating family relations. The ways in which they manage - or try to manage - their health may be seen as expressions of social suffering. As exemplified above, Fanny makes the appointment with her GP 
when her meeting with the social services is imminent, when she expects further demands to be made on her working situation. Her pain is objectified as the basis of her suffering, while her other (and potentially more serious) health concerns are left unattended. And as we have just seen, Brian continuously stresses the need for the GP to approach him as “a whole person,” and tries to draw attention to his physical as well as social impediments. When the GP tries to accommodate this by offering a general health check, Brian resigns and disassociates himself from medical care.

\section{CONCLUDING REMARKS}

We have illustrated how health care seeking practices materialize in different social classes by drawing on exemplary cases. Notions of proactivity and individual responsibility inherent in the move towards health consumerism are more successfully adopted by the HMC than the LWC, supporting arguments raised in earlier studies (Lupton 1995, Rose 2007, Shilling 2002). By linking differences in health care seeking practices to diverse social classes, we argue for differences of degrees not absoluteness of practices. The discursive and social conditions framing health care seeking practices are manifested in degrees of social suffering, which illustrates how bodily attentiveness and the ways in which trouble and illness are dealt with are embedded in social and cultural contexts; here, social suffering and health consumerism are to some extent at odds with each other.

Cancer was introduced to challenge the assumption that raising public knowledge and awareness of potential 'alarm symptoms' is a magic bullet to encourage early health care seeking practices and so reduce inequality in the diagnosis of cancer (e.g. Ibfelt et al. 2012, Lyratzopoulos and Abel 2013, Quaife et al. 2015). The cancer case also emphasizes the complexities of current 
forms of medical care, wherein expectations of patient responsibility and bodily sensitivity are increasing, further complicating the process of performing and responding correctly to the expectations of the health care system. The focus on identifying 'alarm symptoms', as advocated by discourses on early health care seeking and cancer diagnosis, rests on the assumption that 'proper' knowledge and awareness will lead to the prescribed forms of health care seeking practices. Indeed, raising awareness may invite health care seeking practices, as found in the HMC and illustrated by Esther and Charlotte. Yet, Brian's and Fanny's social suffering illustrates how the sole approach to care seeking from the perspective of increasing knowledge and awareness may ignore the ambiguity characterizing health care seeking practices among people in disadvantaged situations which may have little to do with levels of information. Illness signs and worries, promoted in early health care seeking discourses, overlook the complexity of people's experiences. Health care seeking is not just a matter of going to see the doctor (Andersen, Tørring and Vedsted 2014); it is socially situated and sanctioned, embedded in the practice of everyday life, and it resonates differently from the current cancer and early diagnosis discourse.

Knowledge and empowerment is not a magic bullet that can improve early care seeking. It has argued that health care seeking practices play into 'a clinical logic' wherein the established frames for legitimate health care seeking encourage specific, singular, and well-defined presentations of medical problems in the clinical encounter (Andersen, Tørring and Vedsted 2014). Mik-Meyer and Obling (2012) draw attention to the ways in which medical truths lay out the rules for how health problems enter into the consultation. It seems plausible that behavioral requirements labelled as attentiveness, proactivity and individual responsibility, more recently camouflaged in parts of the public health literature in terms of patient empowerment and involvement (McDonald, Bryce, and Graber 2013), and promoted by the service user perspective, can be connected with the social (and 
class based) distinction of the 'proper' patient role. Aimed at enhancing patient responsibility for illness prevention and treatment (e.g. early care seeking, participation in screening, and various selfcare regimes), these 'service user' initiatives, rolled out in the health care system during the past years, promote patient centeredness, materializing as an institutionalized version of health consumerism. However, they run the risk of contrasting the social suffering of people with illness trajectories similar to those of Brian and Fanny, by solely focusing on the patient populations who are able and willing to be empowered, participate in decision-making, and play a leading part in managing their illness own. This leads us to suggest that health promotion discourses encouraging early healthcare seeking are based on assumptions that reverberate in empowerment and patient involvement strategies - assumptions which may, in fact, serve to perpetuate the very social inequalities in health that they seek to alleviate.

\section{FUNDING:}

This article was funded by the Danish Cancer Society, the Novo Nordisk Foundation and the Faculty of Health, Aarhus University. 


\section{REFERENCES}

American Anthropological Association.

2012 Principles of Professional Responsibility. Ethics Blog. Full Text of the 2012 Ethics

Statement. http://ethics.aaanet.org/category/statement/.

Andersen, J. H. and Whyte, S. R.

2014 Measuring risk, managing values: health technology and subjectivity in Denmark. Anthropology \& Medicine 21(3): 265-76.

Andersen, R. S., M. L. Tørring, and P. Vedsted

2014 Global health care-seeking discourses facing local clinical realities: exploring the case of cancer. Medical Anthropology Quarterly 29(2): 237-55.

Bernard, H. R.

2011 Research Methods in Anthropology: Qualitative and Quantitative Approaches. Oxford: AltaMira.

Bourdieu, P.

1984 Distinction: A Social Critique of the Judgement of Taste. Cambridge, MA: Harvard University Press. 
1987 What makes a social class? On the theoretical and practical existence of groups.

Berkeley Journal of Sociology 32: 1-17.

Baadsgaard, M. and H. Brønnum-Hansen

2012 Social Ulighed i Levetiden. http://www.ae.dk/files/dokumenter/analyse/ae_socialulighed-i-levetid_0.pdf.

Ceres, $\mathrm{V}$.

2011 Social suffering and the embodiment of the world: Contributions from anthropology. RECIIS (Revista Eletrônica de Comunicação, Informação \& Inovação Em Saúde) 5(4): 3-13.

Clifford, J.

1997 Spatial practices. Fieldwork, travel, and the disciplining of anthropology. In

Anthropological Locations: Boundaries and Grounds of a Field Science. J. Gupta, Akhil and Ferguson, eds. Pp. 185-222. Berkeley and Los Angeles, CA: University of California Press.

Coleman, M. P. D. Forman, H. Bryant, J. Butler, B. Rachet, C. Maringe, U. Nur, et al.

2011 Cancer survival in Australia, Canada, Denmark, Norway, Sweden, and the UK, 19952007 (the International Cancer Benchmarking Partnership): An Analysis of PopulationBased Cancer Registry Data. Lancet 377 (9760): 127-38. 
Conrad, P., ed.

2007 The Medicalization of Society. Baltimore: John Hopkins Univeristy Press.

Dalton, S. O., B. L. Frederiksen, E. Jacobsen, M. Steding-Jessen, K. Østerlind, J. Schüz, M. Osler, and C. Johansen.

2011 Socioeconomic Position, Stage of Lung Cancer and Time between Referral and Diagnosis in Denmark, 2001-2008. British Journal of Cancer 105(7): 1042-48.

Dalton, S. O., M. Steding-Jessen, M.Gislum, K. Frederiksen, G.Engholm, and J. Schüz.

2008 Social inequality and incidence of and survival from cancer in a population-based study in Denmark, 1994-2003: Background, aims, material and methods. European Journal of Cancer 44(14): 1938-49.

Emerson, R. M., R. I. Fretz, and L. L. Shaw, eds.

2010 Writing Ethnographic Fieldnotes. Chicago: Chicago Univeristy Press.

Frederiksen, B. L., M. Osler, H. Harling, and T. Jørgensen

2008 Social inequalities in stage at diagnosis of rectal but not in colonic cancer: A nationwide study. British Journal of Cancer 98(3): 668-73.

Garro, L. C. 
2011 Enacting ethos, enacting health: Realizing health in the everyday life of a California family of Mexican descent. Ethos 39(3): 300-330.

Hamilton, W., R. Lancashire, D. Sharp, T. J. Peters, K. Cheng, and T. Marshall

2009 The risk of colorectal cancer with symptoms at different ages and between the sexes: A case-control study. BMC Medicine 7(1): 17.

Ibfelt, E., S. K. Kjær, C. Johansen, C. Høgdall, M. Steding-Jessen, K. Frederiksen, B. Lidegaard Frederiksen, M. Osler, and S. O. Dalton

2012 Socioeconomic position and stage of cervical cancer in Danish women diagnosed 2005 to 2009. Cancer Epidemiology Biomarkers and Prevention 21(5): 835-42.

Jöhncke, S.

2011 Integrating Denmark: The wellfare state as a national(ist) accomplishment. In The Question of Integration. Immigration, Exclusion and the Danish Wellfare State, K. F. Olwig and K. Pæregaard, eds. Pp. 30 - 53. Newcastle upon Tyne: Cambridge Scholars.

Karasz, A. and K. Dempsey

2008 Health seeking for ambiguous symptoms in two cultural groups: A comparative study. Transcultural Psychiatry 45(3): 415-38.

Katz, S. 
2000 Busy bodies: Activities, aging, and the management of everyday life. Journal of Aging Studies 14(2): 135-52.

Kleinmann, A, V. Das, and M. Lock, eds.

1997 Social Suffering. Berkeley: University of California Press.

Larsen, E. L.

2010 Community Participation in Health Promotion. PhD Dissertation, Faculty of Health Sciences, University of Southern Denmark.

Lupton, D

1995 The Imperative of Health: Public Health and the Regulated Body. London: SAGE Publications.

1997 Consumerism, reflexivity and the medical encounter. Social Science \& Medicine 45(3): 373-81.

Lyratzopoulos, G, G A Abel, C H Brown, B A Rous, S A Vernon, M Roland, and D C Greenberg. 2013 Socio-demographic inequalities in stage of cancer diagnosis: Evidence from patients with female breast, lung, colon, rectal, prostate, renal, bladder, melanoma, ovarian and endometrial cancer. Annals of Oncology: Official Journal of the European Society for Medical Oncology / ESMO 24(3): 843-50. 
Macleod, U., E. D. Mitchell, C. Burgess, S. Macdonald, and A. J. Ramirez

2009 Risk factors for delayed presentation and referral of symptomatic cancer: Evidence for common cancers. British Journal of Cancer 101 Suppl (S2): S92-101.

McDonald, K. M., C. L. Bryce, and M. L. Graber

2013 The patient is in: Patient involvement strategies for diagnostic error mitigation. BMJ Quality \& Safety 22, Suppl 2: ii33-39.

Mik-Meyer, N. and A. R. Obling

2012 The negotiation of the sick role: General practitioners' classification of patients with medically unexplained symptoms. Sociology of Health \& Illness 34(7): 1025-38.

Olsen, L., N. Ploug, L. Andersen, and J. S. Juul.

2012 Det Danske Klassesamfund. København: Gyldendal.

Ortner, S. B.

2003 New Jersey Dreaming: Capital, Culture, and the Class of ‘58. Durham, NC: Duke University Press.

Pickett, K. E., and R. G. Wilkinson

2014 Income inequality and health: A causal review. Social Science \& Medicine 128: 31626. 
Quaife, S., L., K. Winstanley, K. A Robb, A. E. Simon, A. J. Ramirez, L. J. L. Forbes, K. E. Brain, A. Gavin, and J. Wardle

2015 Socioeconomic inequalities in attitudes towards cancer: An international cancer benchmarking partnership study. European Journal of Cancer Prevention : The Official Journal of the European Cancer Prevention Organisation (ECP) 24(3): 253-60.

Rachet, B., L. Ellis, C. Maringe, T. Chu, U. Nur, M. Quaresma, A. Shah, et al.

2010 Socioeconomic inequalities in cancer survival in England after the NHS cancer plan. British Journal of Cancer 103(4): 446-53.

Rose, N.

2007 The Politics of Life Itself. Princeton, NJ: Princeton University Press.

Sabiers, S. E. and H. B. Larsen

2014 De Sociale Klasser I Danmark.

http://www.ae.dk/sites/www.ae.dk/files/dokumenter/analyse/ae_indkomster-i-de-socialeklasser-i-2012_0.pdf.

Shilling, C.

2002 Culture, the 'sick role' and the consumption of health. The British Journal of Sociology 53(4): 621-38.

Statens Serum Institut 
2013 Dødsårsagsregisteret 2012. Tal Og Analyse. (Cause of Death Register 2012. Figures and Analysis).” http://www.ssi.dk/ /media/Indhold/DK dansk/Sundhedsdata og it/NSF/Registre/Dodsaarsagsregisteret/D\%C3\%B8ds\%C3\%A5rsagsregisteret 2012.ashx.

Svendsen, R. P., H. Støvring, B. L. Hansen, J. Kragstrup, J. Søndergaard, and D. E. Jarbøl

2010 Prevalence of cancer alarm symptoms: A population-based cross-sectional study. Scandinavian Journal of Primary Health Care 28(3): 132-37.

Whitaker, K. L., U. Macleod, K. Winstanley, S. E. Scott, and J. Wardle

2015 Help seeking for cancer 'alarm’ Symptoms: A qualitative interview study of primary care patients in the UK. British Journal of General Practice 65(631): e96-105.

Whyte, S. R.

2009 Health identities and subjectivities: The ethnographic challenge. Medical Anthropology Quarterly 23(1): 6-15.

Willems, S., S. De Maesschalck, M. Deveugele, A. Derese, and J. De Maeseneer

2005 Socio-economic status of the patient and doctor-patient communication: Does it make a difference? Patient Education and Counseling 56(2): 139-46.

Woods, L. M., B. Rachet, and M. P. Coleman 
2006 Origins of socio-economic inequalities in cancer survival: A review. Annals of Oncology 17(1): 5-19. 